\title{
FEMINILIDADE COERCITIVA: OS ARQUÉTIPOS FEMININOS NA PUBLICIDADE COMO ESTRATÉGIA DE MANUTENÇ̄̃̃O DA COERÇ̃̃O SOCIAL
}

\author{
COERCIVE FEMININITY: FEMININE ARCHETYPES IN \\ ADVERTIIING AS A STRATEGY OF MAINTAINING SOCIAL COERCION
}

\section{RESUMO}

Este artigo tem como objetivo debater o uso dos arquétipos femininos pela publicidade apresentados na obra de Sal Randazzo como um reforço da ideia de feminilidade construída socialmente. O aporte teórico sobre o conceito de feminilidade inclui autoras como Naomi Wolf, Simone de Beauvoir e Judith M. Bardwick. Para a compreensão sobre noções da área da publicidade foram citados Sut Jhally, Jorge Maranhão e do próprio Randazzo. Por meio da discussão dos conceitos e do uso de exemplos de peças publicitárias de empresas de diferentes setores, foi possível apontar que o uso dos arquétipos femininos pela publicidade ajuda a construir uma noção de feminilidade que restringe as percepções de atuação da mulher e age em favor da manutenção das coerções sociais a ela impostas.

Palavras-chave: Feminilidade. Coerção social. Arquétipos femininos. Publicidade.

\begin{abstract}
This article aims to discuss the use of the feminine archetypes by the publicity presented in the work of Sal Randazzo as a reinforcement of the idea of socially constructed femininity. The theoretical contribution on the concept of femininity includes authors like Naomi Wolf, Simone de Beauvoir and Judith M. Bardwick. The basis for the understanding about notions of the area of the publicity was the work of Sut Jhally, Jorge Maranhão and Randazzo. Through the discussion of the concepts and the use of examples of publicity pieces of companies from different sectors, it was possible to point out that the use of the feminine archetypes by advertising helps to construct a notion of femininity that restricts women's perceptions of action and acts in favor of the social coercion imposed on it.
\end{abstract}

Keywords: Femininity. Social coercion. Feminine archetypes. Advertising.

Beatriz Molari

UEL. Email: beatriz.molari@gmail.com 


\section{Introdução}

Os profissionais da área da publicidade sempre estiveram em busca de estratégias para promover o consumo, a principal delas envolve a criação dentro do anúncio de um mundo próprio e no qual tem como protagonista o produto e os benefícios para o seu comprador. Dentro desta estratégia, os arquétipos foram adotados pela publicidade com o objetivo de promover a identificação da figura representada pelo público. Contudo, este processo envolve mais do que a promoção do consumo. Os arquétipos são incorporados ao subconsciente dos indivíduos e os conceitos que os envolvem são adotados como referência na interação com o outro. No caso dos arquétipos femininos, suas características são empregadas na construção da ideia de feminilidade e interferem na compreensão que a sociedade tem sobre a atuação da mulher. Partindo deste conhecimento, este artigo promove uma discussão sobre a o uso dos arquétipos femininos na publicidade no processo de construção de uma feminilidade que é empregada como forma de coerção social da mulher. Para exemplificar os conceitos debatidos, foram incorporados ao estudo imagens de peças publicitárias de diferentes marcas e distintas em categoria de consumo e ano de divulgação.

\section{Publicidade e os arquétipos femininos}

O sistema econômico capitalista é baseado na manutenção de bens privados e na livre atuação do comércio de bens de serviços. O principal objetivo do capitalismo é a geração de lucro, e, para que isto seja alcançado, executam-se estratégias que fomentam o consumo. Neste cenário, a publicidade é a principal atividade comunicacional de promoção de produtos e serviços. Segundo Sut Jhally (1995: 13), "ao nível material, concreto e histórico, a publicidade tem a ver, especificamente, com a comercialização de bens, e ascendeu a um plano de proeminência na sociedade moderna enquanto discurso através e acerca dos objetos" (grifos do autor). O autor ressalta a estreita relação da publicidade com os objetos, a qual rege a comunicação entre empresas e consumidores. Este caráter comunicacional da publicidade é ressaltado por Jorge Maranhão ao definir publicidade como o ato de "[...] dar destaque público a determinado assunto, principio, ideia, etc.” (MARANHÃO, 1988: 41). O autor complementa dizendo que a publicidade pode ser compreendida em sociedade como uma prática discursiva organizada comercialmente, sendo "[...] o registro da persuasão do discurso, sua totalidade, seus recursos retóricos padrões que têm como fim último exaltar os méritos do objeto cultural, um produto ou serviço" (MARANHÃO, 1988: 45). Este discurso é aplicado pela publicidade em um cenário com dois polos: de um lado a empresa que quer vender algum produto ou serviço; e do outro os possíveis consumidores. Para que a comercialização seja concretizada, a publicidade cria um mercado que aceite o produto em questão e desenvolve uma 
comunicação com os consumidores. Para Jhally a publicidade atua com a criação de falsas necessidades nos indivíduos, isto na medida em que, segundo o autor, são necessidades das empresas que querem vender algo e não dos consumidores (JHALLY, 1995). Observa-se que na relação entre empresas e consumidor regida pela publicidade, acontece o processo de objetificação das pessoas, ou seja, as mesmas são vistas na medida em que podem adquirir o objeto comercializado. Não se trata de um indivíduo que possui necessidades e desejos, mas é enquanto indivíduo consumidor que a sua relevância se torna importante para a publicidade. Isto, segundo Jhally é parte da "materialidade do mundo concreto" (JHALLY, 1995: 14).

A comunicação feita pela publicidade é feita em maioria através de anúncios. Estes são veiculados em diferentes meios de comunicação, como a mídia impressa, televisiva ou online, esta principalmente nas redes sociais. A criação de plataformas digitais que permitem a interação entre empresa e público possibilitou o contato quase direto com o público. Contudo, independente do meio de comunicação, os anúncios sempre são transmitidos com o mesmo propósito que é despertar no possível consumidor o desejo pelo produto e então concretizar a comercialização. Para Jhally, os anúncios mostram as mercadorias como mediadores da relação entre indivíduos e as expectativas que os mesmos adquirem ao visualizar o anúncio (JHALLY, 1995). Estas expectativas e desejos são criados com base no mundo lúdico do anúncio. Para Oliviero Toscani, a "publicidade excita os seus desejos, seduz os ingênuos, cria-lhes necessidades, torna-os culpáveis. Ela nos atrai para os seus encantos, nos 'acende' através de técnicas experimentais" (TOSCANI, 1996: 29). Os encantos aos quais o autor se refere estão presentes nos símbolos utilizados nos anúncios. Cada anúncio possui um "roteiro" e personagens que comunicarão a mensagem ao público. Para Sal Randazzo o mundo criado pela publicidade possui personagens míticos que são associados ao produto. Assim, os significados associados pelo público à marca serão aqueles que a publicidade comunicar (RANDAZZO, 1996). Dessa forma, pode-se dizer que a publicidade ajuda a moldar a concepção que o público tem de determinada marca e produto através do uso de mitologias.

Para Randazzo, a publicidade faz uso de mitologias para fortalecer a marca ou um produto. O autor afirma que um produto possui uma mitologia latente que "[...] abarca a totalidade das percepções, crenças, experiências e sentimentos associados com o produto" (RANDAZZO, 1996: 25). Segundo o autor, esta mitologia é baseada em experiências do consumidor com a categoria do produto e as histórias incorporadas ao mesmo. Trata-se de criar toda uma bagagem de manifestações populares acerca de um produto e, apropriando-se destas, compor uma mitologia própria. No caso de uma marca, a mitologia acerca da mesma é “[...] tudo aquilo que a marca representa na mente do consumidor. É geralmente uma mistura de imagens, símbolos, sentimentos e valores que resultam do inventário perceptual específico da marca, e que coletivamente definem a marca na mente do consumidor" (RANDAZZO, 1996: 29). Seja no caso de um produto ou uma marca, a publicidade pode ser aplicada para reforçar as percepções que o consumidor já possui ou para associar novos símbolos. Neste ponto entra a questão do uso de elementos em peças publicitárias, o que pode 
ser feito através de associações com objetos, conceitos ou mesmo personagens. Sobre este ponto, Randazzo afirma que

A publicidade funciona como uma forma romanceada de comunicação, uma ficção narrativa que usa personagens, lugares e situações fictícios, e assim por diante, a fim de envolver e interessar o consumidor, comunicar os atributos e benefícios da marca (físicos e emocionais), e posicionar perceptualmente a marca na mente do consumidor. A publicidade nos garante acesso à mente do consumidor, onde podemos criar mundos e personagens míticos, atraentes. Todas as imagens, todos os símbolos, sentimentos e associações criados e transmitidos pela publicidade se tornam partes do inventário perceptual da marca (RANDAZZO, 1996: 29).

O “inventário perceptual da marca” é construído e fortalecido constantemente pela publicidade. $\mathrm{O}$ uso de personagens ativa o processo de desenvolvimento da "imagem do usuário", termo elaborado por Randazzo e que trata da "descrição do tipo de pessoa que o anunciante deseja retratar como usuária dos seus produtos" nos anúncios publicitários (RANDAZZO, 1996: 36). Segundo o autor, a imagem do usuário é empregada com o objetivo de criar afinidade entre a marca e o público. "Em outras palavras, o(a) consumidor(a) deve olhar para o anúncio e dizer a si mesmo ou a si mesma: 'Aquela pessoa se parece um bocado comigo ou com a pessoa que eu gostaria de ser. Talvez fosse melhor eu passar a usar aquela marca"' (RANDAZZO, 1996: 36). O autor explica que a imagem do usuário pode ser um usuário real (é o caso de campanhas publicitárias com consumidores reais); um usuário idealizado, ou seja, um personagem criado dentro de uma mitologia: um arquétipo. Randazzo explica que "cada arquétipo tem o seu próprio grupo de símbolos ou cânone de símbolos que também é criado e guiado pelo inconsciente" (RANDAZZO, 1996: 69). O arquétipo adquire forças quando os indivíduos respondem a sua interação no nível consciente e inconsciente, este mais profundo e dificilmente de ser alterado.

Os arquétipos estão relacionados a elementos simbólicos de uma sociedade. Com isso em mente, compreende-se que a representação de arquétipos nos meios de comunicação produz um processo dentro da sociedade, pois a forma que o inconsciente social concebe um indivíduo está relacionada com as mitologias que envolvem o mesmo e estas influenciam a construção social de um indivíduo. Randazzo afirma que os arquétipos são utilizados pela publicidade como uma forma de reafirmar a identidade do consumidor, identificando-se com a imagem do usuário criada pela publicidade e relacionando o uso do produto as semelhanças entre personagem da publicidade e consumidor (RANDAZZO, 1996). Com base nisto, o objetivo deste estudo é investigar o uso pela publicidade dos arquétipos femininos empregados na construção de um conceito de feminilidade que fortalece algumas coerções sociais impostas a mulher. 
Randazzo apresenta uma divisão dos arquétipos baseada no que o autor propõe ser o conceito de identidade de gênero. Para o autor, a identidade de gênero "[...] indica aqueles aspectos da identidade ou autoimagem de um indivíduo que se relacionam com o gênero" (RANDAZZO, 1996: 95) e estão relacionados com os conceitos de masculinidade de feminilidade. O autor ressalta que os publicitários podem fazer uso de arquétipos para reforçar a autoimagem de um gênero. Sobre este aspecto é importante ressaltar a diferença entre gênero e sexo. $\mathrm{O}$ sexo entra na categoria da fisiologia dos indivíduos, sendo determinado pela diferenciação dos órgãos reprodutores. O gênero, por sua vez, está inserido nas estruturas sociais e é determinado com base em tabus, leis, valores e conceitos formulados no meio social, como ressalta Simone de Beauvoir ao dizer que "não é um corpo, é enquanto corpos submetidos a tabus, a leis, que o sujeito toma consciência de si mesmo e se realiza: é em nome de certos valores que ele se valoriza. E, diga-se mais uma vez, não é a fisiologia que pode criar valores" (BEAUVOIR, 2016: 64). Michele Perrot reforça esta ideia afirmando que o gênero é oposto ao sexo biológico e designa as relações dos indivíduos pela cultura e a história (PERROT, 2009). Dessa forma, o uso de arquétipos femininos pela publicidade é um reforço aos conceitos de gênero determinados pela sociedade e não aquele primeiramente escolhido pelo indivíduo em sua subjetividade.

O estudo de Randazzo parte dos trabalhos de Carl Gustav Jung, psiquiatra e psicoterapeuta, e de seu aluno Erich Neumann, psicólogo e escritor. Os arquétipos femininos são divididos em "feminino estático" e "feminino dinâmico". Segundo Randazzo, o aspecto estático feminino é manifestado pelo arquétipo da Grande Mãe. De acordo com o autor, "a Grande Mãe é uma imagem feminina universal que mostra a mulher como eterno ventre e eterna provedora" (RANDAZZO, 1996: 103). O autor complementa dizendo que o aspecto positivo deste arquétipo está representado nos conceitos de "útero da vida" (RANDAZZO, 1996: 104). Nota-se que este arquétipo tem como base o processo de gestação de um indivíduo no útero de uma mulher, o que, como determinado socialmente, torna uma mulher mãe. $\mathrm{O}$ autor apresenta conexões entre conceitos desenvolvidos socialmente sobre a maternidade ao arquétipo Grande Mãe, como proteção, nutrição (alimentação do feto pela placenta no útero durante o processo de gestação e posteriormente representado pela amamentação) e segurança. Randazzo dedica mais algumas linhas na descrição deste arquétipo, mas sempre reafirmando esta associação com a reprodução, o que restringe a Grande Mãe a uma figura que representa a maternidade e dedicada as suas crias.

Opondo-se preliminarmente ao arquétipo apresentado anteriormente, o arquétipo feminino dinâmico é denominado como a Virgem/Donzela. Randazzo descreve este arquétipo como "a noção da mulher fascinante, sedutora e fatal, assim como o arquétipo da mãe provedora, é uma imagem arquetípica primordial da mulher. Exemplos deste arquétipo podem ser encontrados nas musas, nas fadas e nas jovens virgens da literatura" (RANDAZZO, 1996: 115). As palavras "fascinante", "sedutora", "fatal" e "musas" demonstra que este arquétipo está relacionado com a aparência física da personagem feminina. Compreendendo a influencia dos arquétipos na vida 
dos indivíduos, o autor sugere que as mulheres espelham-se nos arquétipos e busca de adquirir as características que o representam. Sobre esta questão o autor afirma que

\begin{abstract}
A beleza sempre foi um aspecto importante da feminilidade. A beleza de uma mulher está ligada à sua autoestima global e é fonte de poder sobre os homens. As garotas percebem muito cedo que podem ter um efeito poderoso sobre os homens. Nos anos 6o, entretanto, o movimento feminista atacou os conceitos de beleza e sexualidade feminina existente. Em parte, as feministas reagiram contra "a aparência loura e burra de bonequinha Barbie", que se tornara um clichê cultural, e acusaram a ideia da beleza feminina por considerá-la "passiva". O movimento feminista procurou negar que a beleza e a sexualidade da mulher eram aspectos da feminilidade - aspectos que as mulheres pareciam apreciar e que lhes davam um enorme poder sobre os homens (RANDAZZO, 1996: 115).
\end{abstract}

Neste ponto, a afirmação do autor demonstra a sua falta de conhecimento sobre o movimento feminista e suas pautas, sobretudo a terceira onda do movimento e a qual o autor se refere. Na época mencionada pelo autor, o movimento feminista direcionava as suas atuações para a questão da ideologia da beleza imposta às mulheres. Questionou-se o fato da mulher ter a sua capacidade avaliada pela sua aparência física. A mulher era reduzida a uma ideologia da beleza que a condicionava a ter um padrão estético considerado socialmente como ideal. Portanto, não se tratava de exercer algum tipo de poder sobre os homens, pelo contrário, a ideologia masculina que incitava a opressão pela beleza sobre as mulheres. Justamente essa ideia errônea é encontrada nas descrições do autor sobre o arquétipo da Donzela. Randazzo afirma que as sereias e ninfas eram a representação do arquétipo da Donzela nas histórias mitológicas e que o seu equivalente contemporâneo é visto na mulher fatal, qual segundo o autor é uma "[...] mulher cuja beleza e misterioso charme feminino têm um efeito perturbador, hipnótico nos homens - geralmente com resultados desastrosos" (RANDAZZO, 1996: 119). Resumidamente, o arquétipo da Donzela seria representado por uma mulher considerada socialmente como bela e que, por meio dos seus atributos físicos, exerce um poder sobre os homens com o objetivo de causa-lhes algum mal.

Tanto o arquétipo da Grande Mãe quanto o da Donzela são restritivos sobre os conceitos que apresentam. O uso destes arquétipos pela publicidade é problemático na medida em que os mesmos sejam absorvidos pela sociedade como uma realidade e passam a compor conceitos com base em visões igualmente limitadas, como é o caso da feminilidade. 


\section{Feminilidade construída}

O conceito de feminilidade é bastante debatido pela sua aplicação arbitrária como algo natural na mulher. Definido dentro de uma sociedade patriarcal, esta formulação apresenta comportamentos e características do que envolveria ser mulher. Pascale Molinier \& Daniel Welzer-Lang afirmam que "são as relações sociais de sexo, marcadas pela dominação masculina, que determinam o que é considerado "normal" - e em geral interpretado como "natural" - para mulheres e homens" (MOLINIER; WELZER-LANG, 2009: 101). A feminilidade, portanto, é pautada sobre um olhar masculino que dita o que é concebido como ser mulher. Tais concepções acerca da mulher são formuladas para beneficiar os objetivos da dominação masculina, pois "sob o pretexto da feminilidade, as mulheres devem escolher uma aparência que assinale sua interiorização dos códigos estéticos pensados pelos homens, e adotar diante deles uma atitude submissa e não concorrencial quanto ao poder" (MOLINIER; WELZERLANG, 2009: 103). A feminilidade foi moldada para manter a dominação sobre a mulher. Segundo Erika Apfelbaum (2009: 76) uma relação de dominação introduz uma estrutura de valores e normas sociais que são impostas como universais. Dessa forma, é quando a feminilidade é colocada como uma característica de ser mulher que é alcançada a totalidade de sua dominação.

Os argumentos que defendem a feminilidade como algo natural da mulher são baseados principalmente na ideia de que o sexo biológico determina o gênero e este seria responsável por estabelecer desde o nascimento qual será o papel social de um indivíduo. Judith Bardwick contesta esse argumento enfatizando que os sexos partilham das mesmas características como indivíduos sociais e que os papéis sociais são resultado de um processo de aprendizagem vivenciado socialmente (BARDWICK, 1981). A autora completa dizendo que "a inferência desejável é que nenhuma diferença de comportamento significativa tem origem nas diferenças biológicas" (BARDWICK, 1981: 179). Para a autora, a imposição de uma feminilidade contradiz a ideia de identidade do papel sexual, qual se refere à percepção que o indivíduo tem de si, adotando a identidade de masculino ou feminino (BARDWICK, 1981). Logo, feminilidade não se trata da identidade da mulher, mas de uma imposição de terceiros sobre a mulher, o que, portanto, contradiz a ideia de naturalidade.

Outro aspecto relacionado à feminilidade é a questão da aparência física da mulher. Como foi exposta pela frase de Randazzo, a feminilidade concebe que as mulheres se beneficiam caso se mantenham dentro de um padrão de beleza. $\mathrm{O}$ que os autores que defendem a feminilidade não mostram é o custo cobrado às mulheres para que sejam consideradas belas e, portanto, femininas. Naomi Wolf afirma que a ideologia da beleza (ou mito da beleza) determina mais do que a aparência física, são condicionados comportamentos que reprimem a atuação da mulher e tiram da mesma o controle sobre o próprio corpo, de seu psicológico e das oportunidades de carreira (WOLF, 1992). A autora explica que a mulher é prejudicada financeiramente pelo mito da beleza, pois a mesma tem as suas capacidades ignoradas e sua aparência 
supervalorizada quando se trata da sua carreira profissional (WOLF, 1992). Para conseguir melhores oportunidades, a mulher investe dinheiro em cosméticos e serviços estéticos que a ajude a atingir um pouco do padrão idealizado de beleza. Como se nota, a questão da feminilidade como uma forma de exercer poder sobre os homens se mostra equivocada. Oprimidas pelo mito da beleza, as mulheres entram em um estado de vigilância constante de sua aparência que as esgota fisicamente e psicologicamente na busca por um padrão que foi criado para não ser atingido. $O$ resultado disto é que "o mito da beleza gera nas mulheres uma redução do amorpróprio, com o resultado de altos lucros para as empresas” (WOLF, 1992: 64).

A questão da ideologia da beleza é inserida na feminilidade em conjunto com algumas diretrizes para a sexualidade da mulher. Uma mulher bela recebe o título de mulher "fatal", como dito na frase de Randazzo. Contudo, a sexualidade da mulher sempre foi reprimida. São pertinentes as colocações deste autor sobre a sexualidade feminina quando descreve o arquétipo da Donzela. Sabe-se que biologicamente a mulher possui oscilações hormonais no intervalo entre uma menstruação e a seguinte. Aproximadamente no meio deste intervalo, a mulher ovula e o seu corpo começa a se preparar para uma possível fecundação. Este processo exige mudanças drásticas nos níveis de hormônios, o que interfere no seu humor e libido. Randazzo chama este período de "cio" e afirma que a expressão da sexualidade faz parte da natureza da mulher e um aspecto da sua feminilidade (RANDAZZO, 1996). O que chama a atenção na fala do autor é a colocação de que a mulher torna-se "incontrolável”, "selvagem" por ter um desejo sexual maior. $\mathrm{O}$ autor coloca a expressão da libido feminina como oposta a racionalidade e capacidade de controle do próprio comportamento. Este pensamento é fruto de uma concepção patriarcal da sexualidade feminina. Wolf afirma que a ideia de que a sexualidade feminina é menor do que a masculina remete ao final do século XVIII, por volta da ascensão da Revolução Industrial (WOLF, 1998). A autora afirma que a Europa e os Estados Unidos providenciam uma visão que torne a mulher "angelical", ou seja, a mulher decente devia reprimir os seus desejos sexuais e desenvolver a domesticidade (WOLF, 1998). A libido feminina passou a ser vista como algo vergonhoso e em contrapartida, a submissão da mulher foi valorizada pela sociedade. Wolf afirma que a "teoria feminista tradicional ensinou que o medo masculino da sexualidade feminina é meramente uma projeção do desejo masculino e da sua misoginia" (WOLF, 1998: 302), ou seja, a sexualidade feminina é repremida na medida em que os homens temem que a liberdade desta motive as mulheres a buscarem a transformação das estruturas de dominação masculina. Afinal, "se a sexualidade das mulheres não fosse de fato subversiva sob algum aspecto, por que aqueles que procuraram controlar as mulheres tiveram de se esforçar tanto e por tanto tempo?" (WOLF, 1998: 302). O temor de uma revolução das mulheres faz com que coerções sociais sejam criadas pelo olhar masculino com o intuito de controlar o corpo, a sexualidade e toda forma de expressão que demonstre poder. Para Durkheim, as coerções sociais são formuladas pela sociedade e são aplicadas às vivências dos indivíduos independente da sua adoção ou não. Para o autor, é incontestável que as ideias e tendências não são elaboradas pelos indivíduos, mas pelo social, o que 
ressalta o caráter impositivo das coerções sociais (DURKHEIM, 1972). Um exemplo disto é a feminilidade construída abordada neste estudo.

A feminilidade torna-se um conceito construído quando as ideias são baseadas em noções masculinas sobre a mulher, o que torna tal conceito baseado em uma falsa realidade. Em uma sociedade patriarcal, a história das mulheres sempre foi construída de forma diferente dos indivíduos do sexo masculino. Perrot ressalta essa questão:

Há muito tempo que as mulheres são as esquecidas, as sem-voz da História. O silêncio que as envolve é impressionante. Pesa primeiramente sobre o corpo, assimilado à função anônima e interpessoal da reprodução. O corpo feminino, no entanto, é onipresente: no discurso dos poetas, dos médicos ou dos políticos; em imagens de toda natureza - quadros, esculturas, cartazes que povoam as nossas cidades. Mas esse corpo exposto, encenado, continua opaco. Objeto do olhar e do desejo, fala-se dele. O pudor que encobre seus membros ou lhes cerra os lábios é a própria marca da feminilidade (PERROT, 2003: 13).

Formulada em uma sociedade patriarcal, a feminilidade cala a voz das mulheres. Para Beauvoir, as definições da feminilidade diminuem a mulher, pois "espontaneamente, ela escolhe ser um indivíduo completo, um sujeito e uma liberdade diante de quem se abrem o mundo e o futuro: se essa escolha se confunde com a da virilidade, é na medida em que a feminilidade significa hoje mutilação" (BEAUVOIR, 1967: 148). Para a autora, esta imposição da feminilidade tem a ver com as limitações impostas pelo sexo. O seu corpo é visto como determinante de suas atuações no espaço social. A falsa noção de dualidade que prega que a recusa da imposta feminilidade significaria declinar as características femininas, como uma escolha pela virilidade masculina, o que interfere na compreensão da coerção através da feminilidade. Nessa lógica, a escolha pela maternidade significaria a adoção de todo o fardo de conceitos que a feminilidade empregaria, contudo, não é a realidade. A negação da feminilidade reflete o declínio às concepções de terceiros, a predileção pela formação singular de sua pessoa. A aplicação da feminilidade reflete ideias de estruturas de dominação masculina que se beneficiam com a submissão da mulher a tais conceitos. A estrutura de dominação masculina retira, segundo Beauvoir, a liberdade da mulher em troca dos "tesouros falazes de sua 'feminilidade”" (BEAUVOIR, 1967: 489). Não há um cenário passível de escolha pela mulher. "A mulher que se liberta dessa feminilidade quer contudo conservar-lhe as prerrogativas; e o homem exige então que lhe assuma as limitações" (BEAUVOIR, 1967: 488). Nota-se, portanto, que a feminilidade não possui sua origem na mulher, mas como algo construído com o propósito de lhe ser imposto.

Dentro das estruturas dominantes, há aquelas que obtêm lucro com a feminilidade construída, como é o caso da publicidade. A colaboração da publicidade 
na manutenção da coerção social da mulher évista quando as representações femininas são baseadas em visões limitadas, como é o caso dos arquétipos apresentados. Esta questão é abordada no texto a seguir.

\section{A mulher representada pelos arquétipos femininos na publicidade}

No caso dos arquétipos femininos usados na publicidade e apresentados por Randazzo, nota-se que são visões limitadas da mulher. A noção de que os arquétipos expressam fundamentos que são associadas à feminilidade e são empregados com o objetivo de promover a identificação pelo público. O problema do uso destas visões limitadas está no quando as mesmas são vistas como única opção de representação da mulher como Randazzo ressalta ao dizer que "as percepções criadas (ou os mitos perpetuados) pela publicidade podem não ter absolutamente nada a ver com a realidade comportamental. A publicidade cria sua própria realidade. Na publicidade, o que é percebido na mente do consumidor é a realidade mais importante" (RANDAZZO, 1996: 37, grifo do autor). Nestes casos, o uso dos arquétipos na publicidade promove o processo de assimilação das limitações e expansão destas no relacionamento com as mulheres em sociedade, como é o caso da noção de feminilidade. A Grande Mãe remete a domesticidade e maternidade, ideias que se baseiam na teoria patriarcal. Na concepção patriarcal, a domesticidade prega que a atuação da mulher é restrita aos cuidados com a casa e da família. Complementando-se a esta, a ideia da maternidade prega que todas as mulheres possuem um "dom" para serem mães e que este seria o desejo universal dos indivíduos do sexo feminino. Esta assimilação está presente na descrição de Randazzo e é reforçada em peças publicitárias, como a reproduzida abaixo (Figura 1).

O anúncio foi produzido por uma editora e foi veiculado em uma revista impressa e nas redes sociais da marca. A peça traz na parte superior o valor de um salário pago para profissionais de diferentes áreas. A peça em questão foi denunciada ao Conselho Nacional de Autorregulamentação Publicitária (Conar) e sustada por conteúdo machista. 
Figura 1 - Anúncio editora

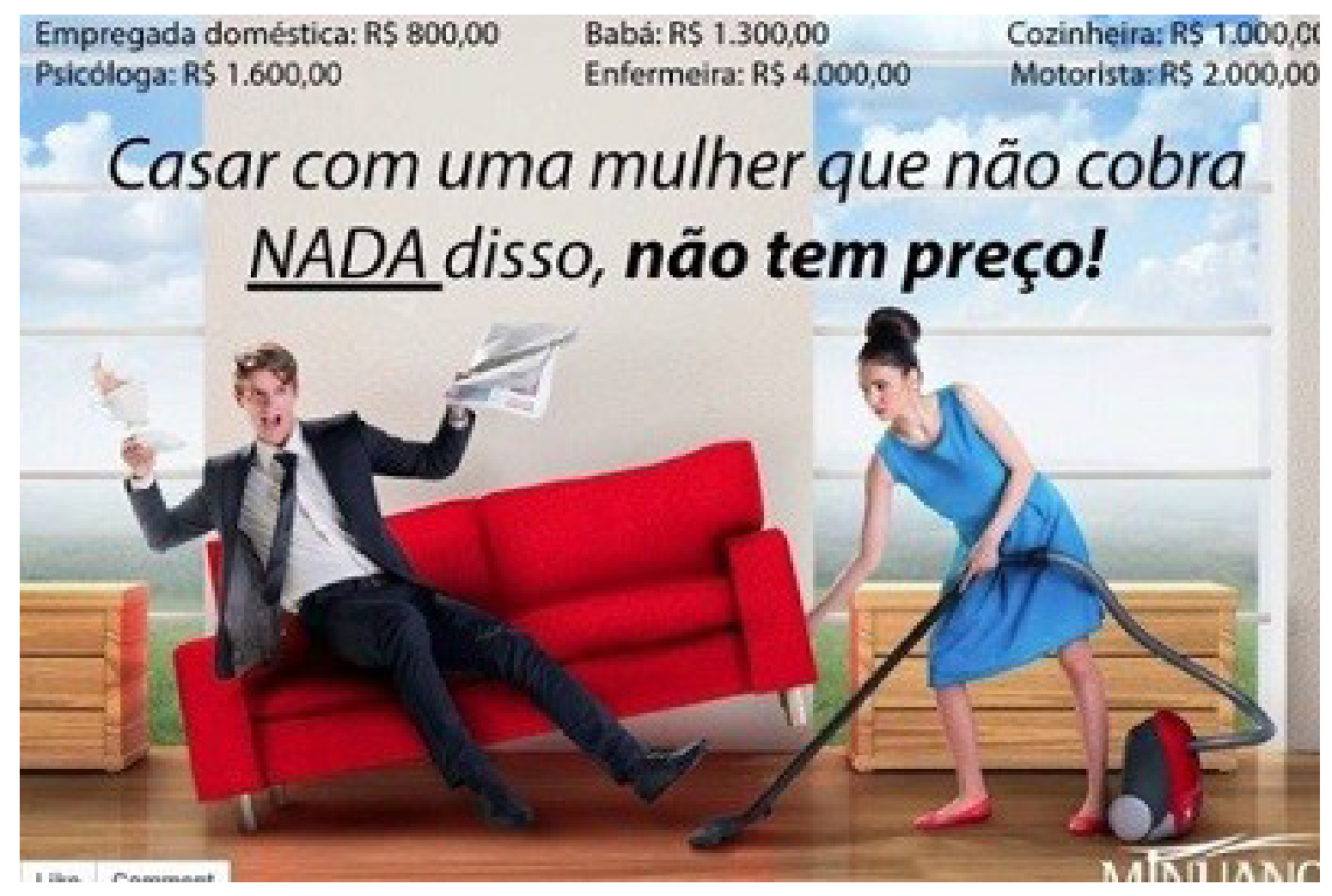

Fonte: GUIMARÃES, 2016.

Ao centro, um homem sentado lendo um jornal e uma mulher levantando o sofá para limpar o piso. As imagens e o texto superior já seriam suficientes, mas o texto ao centro reforça a ideia da domesticidade. Fica nítido pelas imagens e textos que a mensagem transmitida pela editora é de que é obrigação da mulher desempenhar atividades para o cuidado com a casa e também auxiliar o homem e os filhos. Relacionada com o arquétipo da Grande Mãe, essa peça reforça a concepção da mulher devota ao lar. Vista como eterna provedora, a mulher deveria estar disposta a executar tais funções, sendo vistas como o necessário a ser feito após o casamento com um homem. A disposição do corpo da mulher na peça ressalta estas afirmações. Desempenhando uma das funções descritas acima, a imagem reforça por meio da imagem o texto que a acompanha. Além de ilustrar o arquétipo, o corpo da mulher foi representado como uma orientação para a domesticidade. Para Randazzo, a domesticidade seria uma atribuição das mulheres desde que as mesmas são crianças. $\mathrm{O}$ autor reforça que o arquétipo da Grande Mãe condiciona um estado comportamental, ressaltando uma condição que, vista pela publicidade, seria inerente a mulher pelo fato de seu sexo e categorização de gênero.

A segunda imagem (Figura 2) exemplifica o uso do lado materno do arquétipo Grande Mãe. A peça publicitária mostra uma mulher segurando uma criança e ao lado direito o produto. A composição dos elementos sugere que a mulher seja mãe da criança e as imagens são acompanhadas do texto que faz alusão ao uso do produto. 
Figura 2 - Anúncio sabonete

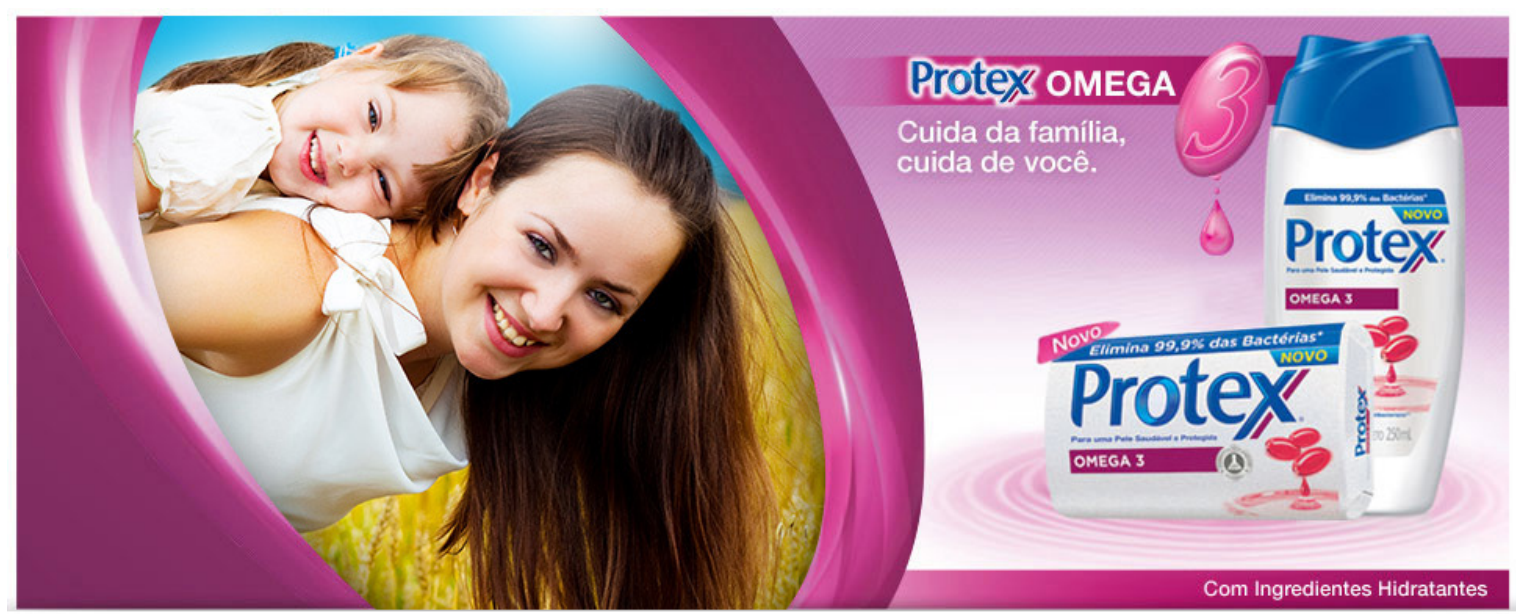

Fonte: PROTEX, 2018.

Neste exemplo a representação da mulher estabelece uma relação com o arquétipo da Grande Mãe ao mostrar a figura feminina como a responsável por cuidar dos demais membros da família. Randazzo afirma que as mulheres são condicionadas desde criança a entenderem a domesticidade como algo natural. Segundo o autor, "as menininhas são encorajadas a serem educadas, sensíveis, gentis e carinhosas. Este papel continua no casamento, quando a mulher adota a arquétipo da Mãe, que mais uma vez exige dedicação e carinho" (RANDAZZO, 1996: 123). O conceito de feminilidade é expresso nestes exemplos ao limitarem a figura feminina a uma função materna e doméstica. Wolf afirma que "através de percepções tão limitadas do universo feminino, as mulheres concluem serem suas opções igualmente limitadas” (WOLF, 1992: 64) e, portanto, não podem se expressar além das representações que lhes são fornecidas.

A relação do arquétipo da Grande Mãe com a feminilidade neste caso está no reforço da posição da mulher como provedora eterna, no sentido de dar a vida (maternidade) e também de conservá-la sendo a cuidadora dos membros da família. A associação feita nesta publicidade está no texto e na imagem. A posição da mulher sustentando a criança e as expressões faciais das duas retratam um estado de segurança. Neste ponto nota-se que a imagem complementa o texto, sendo a ideia central do mesmo transmitir a relação entre o uso do produto e o cuidado para com as pessoas. $\mathrm{O}$ fato de a imagem trazer apenas a mulher e uma criança reforça a concepção de que a mulher seria responsável por ter esse cuidado com os membros de sua família, portanto, representada como a Grande Mãe.

Não só o arquétipo da Grande Mãe é usado pela publicidade brasileira. A imagem arquetípica da Donzela é amplamente empregada em peças publicitárias dos mais diversos setores. As imagens a seguir (Figura 3 e Figura 4) exemplificam este uso. 
Figura 3 - Anúncio cerveja

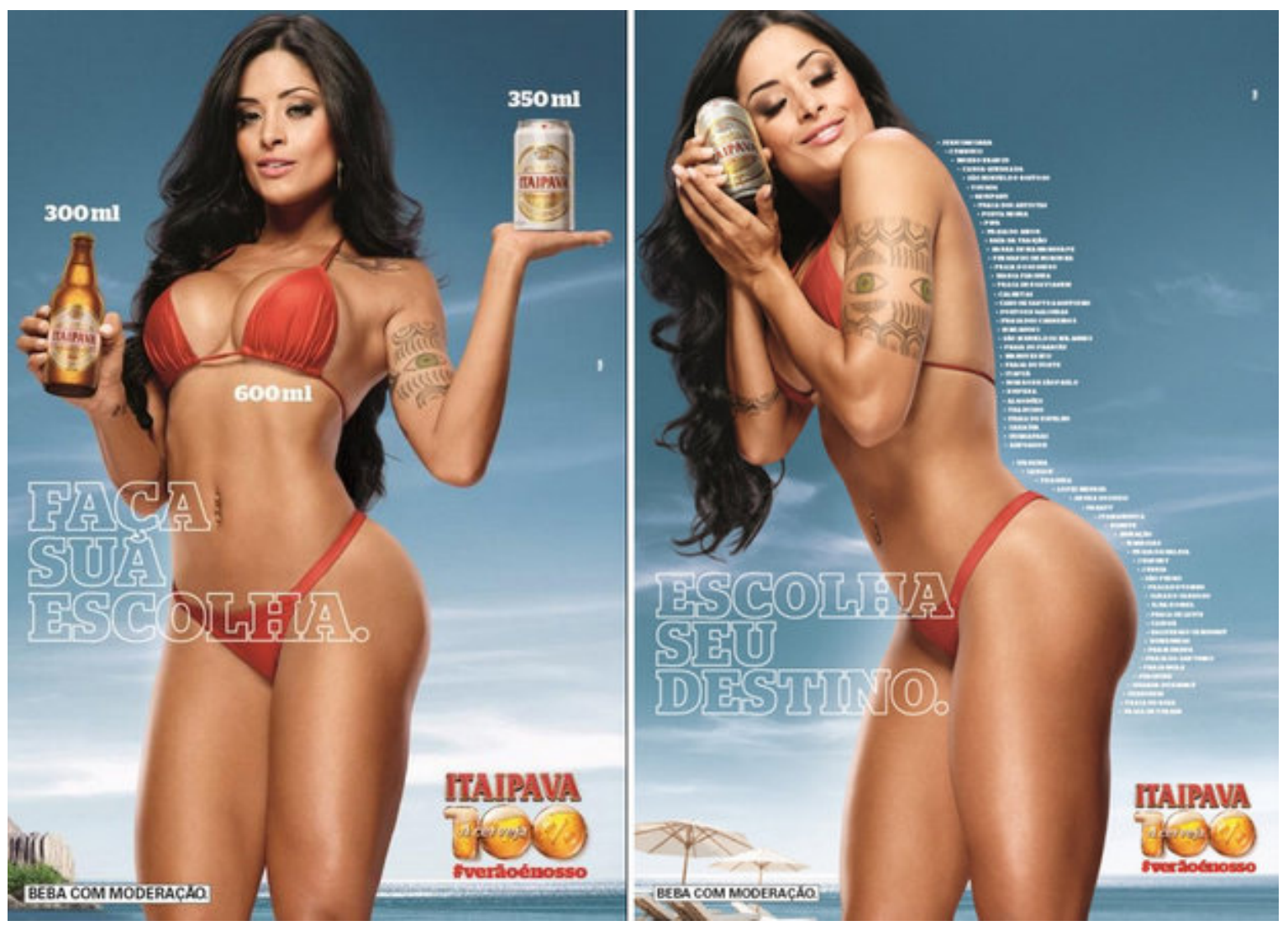

Fonte: CORREIO 24HORAS, 2015.

Os anúncios que mostram representações do arquétipo da Donzela expõem a mulher como um indivíduo extremamente sensual. Características como o uso de uma vestimenta que mostre parte do corpo da mulher e as posições refletem a ideia de mulher fatal apresentada por Randazzo ao falar sobre o arquétipo da Donzela. Algumas categorias de produtos são reconhecidas pelo uso frequente do arquétipo da Donzela, como é o caso da imagem acima que compõe uma peça publicitária de uma marca de cerveja. As peças publicitárias que apresentam este arquétipo frequentemente reproduzem a imagem da mulher em posições sensuais e/ou é sexualizada pelos elementos que compõem a publicidade. No caso da figura acima, além das posições nas quais o corpo da mulher foi exposto, os textos foram organizados de forma a chamar a atenção para o corpo (vide a posição do texto que acompanha o formato do corpo da mulher e as medidas dos mililitros das latas e garrafas sendo colocadas em similaridade com as medidas de um possível uso de silicone nos seios da mulher). Então nesse arquétipo a mulher é reduzida ao seu corpo e exposta como um elemento sexual.

Este tipo de publicidade atua com a ideia de comercializar não só o produto em si (no caso deste anúncio a cerveja), mas de vender a imagem da mulher, tornando-a um atrativo para os consumidores masculinos. Para que este objetivo seja alcançado, é criada toda uma composição da imagem voltada para a sexualidade. A imagem é, portanto, consumida como algo que excita os homens ao ponto de direcioná-los ao 
consumo do produto (e consequentemente, o consumo de mais imagens iguais). $\mathrm{O}$ exemplo da imagem a seguir (Figura 4) reforça essa ideia.

Figura 4 - Anúncio marca de lingerie

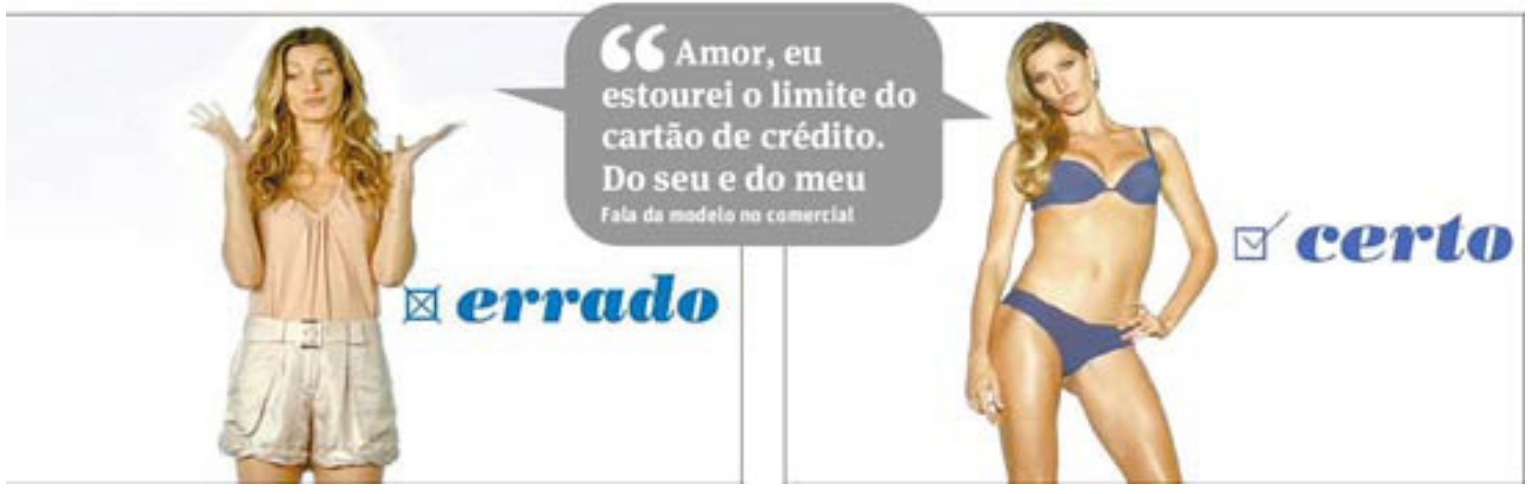

Fonte: FOLHA, 2011.

O uso da figura feminina nesta peça publicitária reforça a ideia de que a sensualidade da mulher pode ser usada como uma forma de conseguir algum proveito do homem. É pertinente a representação da mulher fatal como um indivíduo capaz de desorientar os homens ao ponto de conseguir alguma vantagem. Esta noção remete às sereias, seres subaquáticos que enfeitiçavam os marinheiros para que estes se jogassem no mar e, então, morressem afogados.

No caso da imagem, a apresentação da mulher foi condicionada aos usos de roupas diferentes. A fala da mesma para o seu marido seria igual. Contudo, quando a mesma se apresenta em trajes que cobrem o seu corpo, a sua apresentação é vista como errada; sendo o oposto, quando está trajando apenas peças íntimas, vista como certa. Neste caso, a mulher torna-se irrelevante, sendo o seu corpo desnudo para a apreciação do homem o importante. Com relação ao arquétipo da Donzela, a imagem reforça a concepção de que o corpo feminino, quando empregado como objeto de satisfação sexual do homem, é capaz de confundir a racionalidade do mesmo. Neste ponto, reforça-se que a mulher é reduzida ao corpo e que o homem, o ser racional, perde o controle de si frente a esta característica da mulher. Assim, o corpo da mulher é visto como algo que incita alguma reação irracional em terceiros. Neste ponto, culpabiliza-se a mulher por ações de outros. Tais histórias e suas versões contemporâneas reforçam a ideia patriarcal de que a sexualidade da mulher deve ser controlada, sendo permitida somente quando é para o prazer masculino, como é representado na Figura 3. Esta característica reforça a submissão da mulher e o controle masculino sobre o corpo da mesma, noções presentes na ideia de feminilidade construída culturalmente. 


\section{Considerações finais}

Os arquétipos femininos são usados na publicidade com o intuito de estabelecer no subconsciente dos indivíduos um inventário perceptual da marca que seja acessado no momento do consumo. O processo de identificação do consumidor com o produto promove a assimilação de conceitos às características do personagem na publicidade, o que, consequentemente, estabelece um inconsciente social sobre a figura ali representada. No caso da representação da mulher, o uso dos arquétipos femininos pela publicidade está relacionado com a transmissão de visões limitadas da mulher, reduzindo a sua percepção de atuação e, por conseguinte, colaborando com a manutenção das coerções sociais. Sobre o preceito de feminilidade, as coerções são inseridas a vida da mulher como regras a serem seguidas para que a mesma seja reconhecida com a ideia que a sociedade formou sobre o que envolve ser mulher. Muitas destas regras são estabelecidas por instituições que se beneficiam com a lógica de dominação masculina e, portanto, atuam em favor da sua permanência.

\section{Referências}

APFELBAUM, Erika. Dominação. In: HIRATA, Helena. et al. (orgs.) Dicionário crítico do feminismo. São Paulo: Editora Unesp, 2009. p. 76-80.

BARDWICK, Judith M. Mulher, Sociedade, Transição: como o feminismo, a liberação sexual e a procura da auto-realização alteraram as nossas vidas. São Paulo: DIFEL, 1981.

BEAUVOIR, Simone de. O segundo sexo: fatos e mitos. 3 ed. Rio de Janeiro: Nova Fronteira, 2016.

O segundo sexo: a experiência vivida. 2 ed. São Paulo: Difusão Européia do Livro, 1967.

CORREIO 24HORAS. Conar solicita suspensão de propaganda da Itaipava por ser "sensual demais". Bahia, 19 jun. 2015. Disponível em: < https://www.correio24horas. com.br/noticia/nid/conar-solicita-suspensao-de-propaganda-da-itaipava-por-sersensual-demais/> Acesso em: 15 jul. 2018.

DURKHEIM, E. O que é fato social?. In: DURKHEIM, E. As Regras do Método Sociológico. Trad. por Maria Isaura Pereira de Queiroz. 6. ed. São Paulo, Companhia Editora Nacional, 1972. p. 1-4, 5, 8-11. 
FOLHA. Conar libera propaganda da Hope com Gisele Bündchen. São Paulo, 13 out. 2011. Disponível em: < https://f5.folha.uol.com.br/celebridades/990154-conar-liberapropaganda-da-hope-com-gisele-bundchen.shtml> Acesso em: 15 jul. 2018.

GUIMARÃES, Cleo. Conar atende a denúncias e susta anúncio considerado machista. Rio de Janeiro, 27 mar. 2016. Disponível em: < https://blogs.oglobo.globo.com/genteboa/post/conar-atende-denuncias-e-susta-anuncio-considerado-machista.html> Acesso em: 15 jul. 2018.

JHALLY, Sut. Os códigos da publicidade. Rio Tinto: Edições Asa, 1995.

MARANHÃO, Jorge. A arte da publicidade: estética, crítica e kitsch. São Paulo: Papirus, 1988.

MOLINIER, Pascale. WELZER-LANG, Daniel. Feminilidade, masculinidade, virilidade. In: HIRATA, Helena. et al. (orgs.) Dicionário crítico do feminismo. São Paulo: Editora Unesp, 2009. p. 101-106.

PERROT, Michele. Os silêncios do corpo da mulher. In: MATOS, Maria Izilda S. de. SOIHET, Rachel. (orgs.) O corpo feminino em debate. São Paulo: Unesp, 2003. p. 13-28.

História (sexuação da). In: HIRATA, Helena. et al. (orgs.) Dicionário crítico do feminismo. São Paulo: Editora Unesp, 2009. p. 111-116.

PROTEX. Protex ômega 3. São Paulo. Disponível em: < https://www.protex-soap.com. br/\#omegaz> Acesso em: 15 jul. 2018.

RANDAZZO, Sal. A criação de mitos na publicidade: como publicitários usam o poder do mito e do simbolismo para criar marcas de sucesso. Rio de Janeiro: Rocco, 1996.

TOSCANI, Oliviero. A publicidade é um cadáver que nos sorri. 2 ed. Rio de Janeiro: Ediouro, 1996.

WOLF, Naomi. O mito da beleza: como as imagens de beleza são usadas contra as mulheres. São Paulo: Rocco, 1992.

Promiscuidades: a luta secreta para ser mulher. Rio de Janeiro: Rocco, 1998. 